\author{
Original Article
}

\title{
Efficiency and Accuracy of Three-Dimensional Models Versus Dental Casts: A Clinical Study
}

\author{
Hakan Yılmaz' (D), Fethiye Çakmak Özlü (D), Carmen Karadeniz ${ }^{3}$ (D), Ersan Illsay Karadeniz
}

'Department of Orthodontics, İstanbul Okan University School of Dentistry, İstanbul, Turkey ${ }^{2}$ Department of Orthodontics, Ondokuz Mayıs University School of Dentistry, Samsun, Turkey

${ }^{3}$ Department of Orthodontics, James Cook University College of Medicine and Dentistry, Cairns, Australia

Cite this article as: Cite this article as: Yılmaz H, Çakmak Özlü F, Karadeniz C, Karadeniz El. Time-Efficiency and Accuracy of Three-Dimensional Models Versus Dental Casts: A Clinical Study. Turk J Orthod 2019; 32(4): 214-8.

\section{ABSTRACT}

Objective: The aim of this study was to compare the accuracy of digital and plaster model methods and the time required for analysis. Methods: A total of 30 subjects ( 20 females, 10 males; mean age, $14.36 \pm 6.30$ years), who required plaster models for the construction of either a fixed or a removable orthodontic appliance, were randomly selected. As part of the diagnostic records, digital impressions with a three-dimensional (3D) intra-oral scanner (TriosColor-P13 Shape) were taken from all subjects. Conventional impressions for the orthodontic appliances were taken with alginate (Orthoprint, Zhermack, Italy), and the plaster models were obtained (Scheu-Dental, GmbH.D-58642, Iserlohn, Germany). Two groups were formed. In the conventional measurement group, manual measurements were taken on the plaster models, while in the digital measurement group, the 3Shape OrthoAnalyzer 2013 software was used to make the measurements on the 3D models. In both groups, the total time required to perform the Bolton analysis and space analysis was recorded, and the results were compared.

Results: There was no statistically significant difference found between the two groups in terms of the measurement values. The total time to perform all the analyses was determined to be shorter with digital models compared to conventional plaster models $(p<0.001)$.

Conclusion: The Bolton analysis and space analysis measurements carried out on 3D models did not show any statistically significant difference compared to plaster models. The time taken to perform the analyses was shorter using digital models than for conventional plaster models.

Keywords: Dental models, imaging, three-dimensional, orthodontics, software

\section{INTRODUCTION}

Successful orthodontic treatment is based on a comprehensive diagnosis and treatment planning. One of the diagnostic and treatment planning tools used to determine the degree of obliquity and the incompatibility between the arch shape and tooth dimensions are orthodontic models (1). They are also used for three-dimensional (3D) documentation of the dental arches in pre-treatment, progress, and post-treatment records (2).

In comparison to other methods of documenting treatment records, plaster models require a significant amount of effort to be produced and a storage space because of their size and weight (3). Despite these disadvantages and the risk of models being lost or damaged, plaster models continue to be the gold standard and preferred method in clinical and scientific applications $(4,5)$.

One of the most recent innovations in the field of orthodontics is the introduction of intra-oral scanners, which scan the teeth and surrounding tissues, as an alternative to plaster models (6). Digital models have several advantages, such as the low storage requirement and rapidly obtained data that can be easily sent to the dentist, 
laboratory, or the patient $(7,8)$. Digital models also allow patient-specific virtual "set-up" and advanced treatment planning in both removable and fixed orthodontic appliances $(7,8)$.

Comparisons of digital models and plaster models have been made with respect to diagnostic accuracy and measurement sensitivity $(9,10)$. The space analysis and Bolton analysis are the most commonly used analyses for orthodontic diagnosis and treatment planning in the majority of studies that have compared the digital models and plaster models. The space analysis is traditionally made according to the difference between the mesiodistal dimensions of the teeth in the arch from the mesial of the left molar tooth to the mesial of the right molar tooth and the length of the line forming the parabola of these teeth (11). The Bolton analysis was first used in 1958 with the establishment of two ratios using the total of the mesiodistal widths of the maxillary and mandibular teeth of patients with ideal occlusion (12). Bolton analysis provides clinicians with information about the incompatibility of the tooth size and the amount of deviation from the ideal ratio of the arch dimension (13). Although systematic reviews in the literature could not find any clinically relevant significance of both of these analyses $(14,15)$, there were statistically significant differences in the Bolton analysis in some studies (6). Furthermore, due to the continuous updating of digital modeling methods, examining the importance of reliability, and especially the assessment of time duration, is still ongoing.

Therefore, the purpose of the present study was to compare digital and plaster models with respect to the accuracy and time taken for space and Bolton analyses. The three hypotheses considered were that there was no significant difference between the two methods with respect to space analysis, that there is a statistical difference between the two methods in the proportional comparison in the Bolton analysis, and that there is no difference between the two methods in terms of analysis duration.

\section{METHODS}

The study included 30 patients (20 females, 10 males; mean age, $14.36 \pm 6.30$ years) who presented at the Orthodontics Department of Bulent Ecevit University School of Dentistry to seek orthodontic treatment. The study approval was granted by the Clinical Research Ethics Committee of Bulent Ecevit University.

In addition to the digital impressions taken as routine diagnostic records, a prerequisite for inclusion in the study was the patient requiring either a removable or a fixed orthodontic appliance treatment, for which a plaster model was constructed. For patients who met this prerequisite, the following criteria were examined:

- No previous orthodontic treatment

- The presence of all the permanent teeth from the first right molar to the first left molar

- No absence of any region in the plaster model and digital model

In a total of 30 patients who met the study inclusion criteria, digital impressions were taken using a 3D intra-oral scanner (Trios-
Color-P13 Shape). In addition to the digital impressions taken as routine, impressions were taken with alginate (Orthoprint, Zhermack, Italy) for the fixed or removable orthodontic appliance construction. These impressions were immediately used to obtain plaster models (Scheu-Dental, GmbH.D-58642, Iserlohn, Germany). The study materials comprised 60 models, as 30 plaster models (conventional measurement group) and 30 digital models (digital measurement group) from 30 patients.

The space analysis and Bolton analysis of the obtained digital and plaster models were conducted by the same researcher $(\mathrm{HY})$. To increase the reliability of the measurements, they were repeated five times, and the arithmetic average value was used in the evaluation.

The measurements of the upper and lower arch length in the plaster models were taken with the aid of a brass wire. The mesiodistal width of incisors, canines, premolars, and first molars was measured between the anatomic medial and distal contact points, parallel to the occlusal plane. The anterior and overall Bolton ratios were calculated by dividing the total of the widths of the maxillary teeth by the total of the widths of the mandibular teeth (12). The conventional measurement group model analysis was made with a compass (Münchner Design, 042751-00, Dentaurum). Measurements were made with a specificity of $0.1 \mathrm{~mm}$ because of the needle width of the compass used. The measurement values were recorded to $1 \%(0.01)$ of a millimeter.

In the digital measurement group, the upper and lower arch of each patient was digitized using a Trios 3Shape 3D scanner. The accuracy of this scanner has been listed as 15 microns by the manufacturer. However, previous studies have shown this value to be $25-45$ microns $(16,17)$. Measurements of the intra-oral models obtained with the Trios 3Shape device were made with the OrthoAnalyzer 2013 software program, which is an integral part of the system. For maximum specificity, the magnification as far as the program allowed or a greater proximity to the desired area of the model was used. The time taken to perform the digital and manual measurements was recorded for each sample. In the analyses of both models, distance was measured in millimeters $(\mathrm{mm})$ and time in seconds (sec).

\section{Statistical Analysis}

Statistical analyses were performed using the Statistical Package for Social Sciences version 25.0 software (IBM Corp.; Armonk, NY, USA). The data conformity to normal distribution was assessed using the Shapiro-Wilk test. To analyze the difference between measurement values, the t-test was used for data with normal distribution and the Mann-Whitney U-test for data that did not show normal distribution. A value of $\mathrm{p}<0.05$ was accepted as statistically significant.

\section{RESULTS}

The descriptive statistics of the measurements taken from upper and lower arches in the conventional measurement and digital measurement groups are shown in Table 1. 
Table 1. Descriptive statistics of the measurements made with the conventional and digital methods

\begin{tabular}{|c|c|c|c|c|c|}
\hline Manual measurements & $\mathbf{N}$ & Minimum & Maximum & Mean & SD \\
\hline Space analysis of upper arch $(\mathrm{mm})$ & 30 & -19.36 & 11.46 & -4.63 & 6.23 \\
\hline Space analysis of lower arch (mm) & 30 & -11.53 & 7.36 & -2.57 & 3.76 \\
\hline Bolton ratio of overall & 30 & 85.27 & 103.30 & 91.83 & 3.81 \\
\hline Analysis times (secs) & 30 & 450.00 & 1245.00 & 894.33 & 160.14 \\
\hline Space analysis of lower arch (mm) & 30 & -15.28 & 9.94 & 3.09 & 4.50 \\
\hline Bolton ratio of anterior & 30 & 73.00 & 110.00 & 78.77 & 6.39 \\
\hline Bolton ratio of overall & 30 & 81.00 & 116.00 & 91.60 & 5.43 \\
\hline Analysis times (secs) & 30 & 437.00 & 990.00 & 597.73 & 141.31 \\
\hline
\end{tabular}

Table 2. Comparison between the groups in respect of the space analysis of the two methods

\begin{tabular}{lccccccc} 
& \multicolumn{2}{c}{ Conventional $(\mathbf{N}=\mathbf{3 0})$} & & \multicolumn{3}{c}{ Digital $(\mathbf{N}=\mathbf{3 0})$} & \\
\cline { 2 - 3 } Variables & Mean Rank & Sum of Ranks & & Mean Rank & Sum of Ranks & Z & P \\
Space analysis of Upper arch & 30.70 & 921.00 & & 30.30 & 909.00 & .089 & .929 \\
Space analysis of Lower arch & 31.90 & 957.00 & & 29.10 & 873.00 & .621 & .535 \\
\hline
\end{tabular}

Table 3. Comparison between the groups in respect of the two methods of Bolton analysis

\begin{tabular}{|c|c|c|c|c|c|c|}
\hline \multirow[b]{2}{*}{ Variables } & \multicolumn{2}{|c|}{ Conventional $(\mathrm{N}=30)$} & \multicolumn{2}{|c|}{ Digital $(\mathrm{N}=30)$} & \multirow[b]{2}{*}{$\mathbf{Z}$} & \multirow[b]{2}{*}{ p } \\
\hline & Mean Rank & Sum of Ranks & Mean Rank & Sum of Ranks & & \\
\hline Bolton ratio of anterior & 32.73 & 982.00 & 28.27 & 848.00 & -.992 & .321 \\
\hline Bolton ratio of overall & 31.53 & 946.00 & 29.47 & 884.00 & -.459 & .646 \\
\hline
\end{tabular}

Table 4. Comparison of the Time Taken for the Analyses in Both Methods

\begin{tabular}{|c|c|c|c|c|c|c|c|c|c|}
\hline Variables & \multicolumn{3}{|c|}{ Conventional $(\mathrm{N}=\mathbf{3 0})$} & \multicolumn{3}{|c|}{ Digital $(\mathrm{N}=30)$} & df & $\mathbf{F}$ & $\mathbf{P}$ \\
\hline Analyses times & 908.33 & 136.586 & 24.937 & 577.00 & 95.811 & 17.493 & 51.976 & 4.834 & $.000^{*}$ \\
\hline
\end{tabular}

Before the comparison of two independent groups, a normality analysis was applied. According to the result of the Shapiro-Wilk test, the distribution of the space analysis and Bolton measurements in the conventional and digital models was not normal, but normal distribution was determined in the time measurements. Therefore, the non-parametric Mann-Whitney U-test was used for comparisons of the space analysis and Bolton analysis measurements in the conventional and digital methods, and the parametric t-test was used in the time comparisons.

In the conventional measurement group, the mean space was found to be $4.63 \mathrm{~mm}$ in the upper arch and $2.57 \mathrm{~mm}$ in the lower arch, while in the digital measurement group, these values were $4.38 \mathrm{~mm}$ and $3.09 \mathrm{~mm}$, respectively. No statistically significant difference was found in both groups and measurements ( $p>0.05$ ) (Table 2).

The Bolton overall ratio was mean 91.83 in the conventional measurement group and 91.60 in the digital measurement group. The Bolton anterior ratio was mean 79.16 in the manual measurement and mean 78.76 in the digital measurement. The differences between the digital and manual methods in both the Bolton anterior ratio and the Bolton overall ratio were not found to be statistically significant ( $p>0.05$ ) (Table 3).

The descriptive statistics of the required time to complete the measurements in conventional and digital measurement groups are shown in Table 4. The total time spent for the space analysis and the Bolton analyses that were necessary for orthodontic diagnosis was 894.33 secs for the conventional measurement group and 597.73 secs for the digital measurement group. The digital measurements were completed 296.6 secs sooner than the conventional measurements, and this difference was determined to be statistically significant $(p<0.001)$.

\section{DISCUSSION}

Because of the similarities of the obtained results, the hypothesis that there is no significant difference between the two methods with respect to space analysis was accepted. The hypothesis that there is a statistical difference between the two methods in the proportional comparison in the Bolton analysis was rejected, as both 
the anterior and overall Bolton ratios did not show any statistical difference in the comparison of the two methods. The hypothesis that there is no difference between the two methods in terms of the analysis duration was rejected, as the analysis duration was shorter in digital models compared to conventional models.

In the current study, the inclusion criteria from previous studies were taken as reference $(6,18,19)$. In addition to these criteria, we included plaster and digital models only from subjects who required either the removable or fixed orthodontic appliances treatment.

Several previous studies have compared the accuracy and reliability of plaster models and digital models. However, the majority of those studies obtained the digital model from the plaster model $(3,6,10,18,20-26)$, and only a few studies have used a direct intra-oral scan $(19,27)$. Alcan et al. (28) reported that even if the plaster model was obtained within 1 hour of the alginate measurement taken from the patient, a deviation in the amount of $1.285 \%$ from the main model occurs to be able to register the dental arches with maximum accuracy reduce and to clearly reveal the difference between the two methods, digital models were obtained by direct intra-oral scanning of dental arches.

Since the introduction of 3D digital modeling, its use has been increasing in the field of dentistry. However, only few studies that compared the conventional method with the digital modeling method have used 3D scanning and an analysis software program interface from the same manufacturer (10, 20, 23-25). Several studies have used a different model analysis software not provided by the scanner manufacturer $(3,6,18,19,21,26$, 27). In the current study, the use of the 3Shape scanning system with integral OrthoAnalyzer software allowed an analysis of digital models obtained with a continuous 3D scan system. Furthermore, there was no loss of data or time during the calibration and orientation of 3D images.

The operator reliability is important when taking measurements on digital or plaster models. There can be data loss or deviation because of the learning curve for taking digital and plaster model measurements (29). To reduce these variations to minimum, the measurements of each model were taken five times by a single operator, and the arithmetic average of these measurements was used in the evaluations.

Several studies in the literature have evaluated plaster and digital models with respect to validity and reliability. Despite a statistical difference in some of these studies (21), no clinically significant difference has been determined $(18,22)$. In studies that have found a statistical difference between the two methods, the greatest difference was reported to be $1.48 \mathrm{~mm}$ (30). Profitt et al. (1) reported that a difference of $<1.50 \mathrm{~mm}$ in the model analysis was not clinically significant. The results of the current study support the findings of previous studies as no statistically or clinically significant difference was determined between the two methods with respect to space analysis.
Some previous studies that have compared the Bolton anterior and overall ratios in digital and plaster models have found a statistically significant difference. There are more studies that have reported a statistically significant difference in the Bolton analysis than in the space analysis. However, the mean difference in these studies of 0.05-1.2 $\mathrm{mm}$ was not reported as clinically significant $(6,20,21,23,30)$. The data obtained in the current study were similar, with no statistically or clinically significant difference determined in the Bolton analysis.

Due to a large number of analyses in orthodontic practice, the duration of the analysis can play an important role in the selection of digital or conventional methods. In the current study, which used the 3Shape scanning system with the integral, simple interface of OrthoAnalyzer software, the total duration of the space and Bolton analyses was 894.33 seconds. Using the conventional method, this value was 597.73 secs, and the difference was found to be statistically significant. According to these results, the duration of the analyses made using the digital method was 4.94 mins shorter compared to the conventional method. In a study by Reuschl et al. (25) using the OrthoAnalyzer program, the mean duration of analysis for each model was 2 min shorter than the conventional method, and these results were found to be statistically significant. In another study, the digital analysis was found to be $1 \mathrm{~min}$ shorter than the conventional method (30). In contrast, in a study by Grunheid et al. (19), using a different analysis program, no time difference was found between the two methods. However, in that study, the analysis software program was not compatible with the intra-oral scanning device. In studies related to duration, it is necessary for digital analysis methods to be used at least as much as conventional methods, because mastery of the analysis program and the ease of use of the program interface could change the results.

One of the limitations of the study was that the comparison of the two methods in terms of the duration of analysis did not take into account the total chairside time, which is an important factor for clinicians. Another limitation was that the operator experience and ability were not equal in both measurement methods. In addition, the speed of the digital modeling software program may vary, depending on the version and different hardware specifications. Digital modeling methods and analysis programs are constantly updated and accelerated. Because of this fact, further studies should be carried out taking into account the deficiencies of our study.

\section{CONCLUSION}

The digital analysis method is as reliable as the conventional model analysis method, and it seems to be more time effective. Although some difficulties may be experienced in the manipulation of the digital model analysis software, this method can be sufficient in diagnosing and treatment planning. The major advantages of the digital model software include quick reassessment of the measurements and an easy access to data required for analysis. Therefore, more importance should be given to digital modeling methods and software for clinicians to be able to use them easily. 
Ethics Committee Approval: Ethics committee approval was received for this study from the Clinical Research Ethics Committee of Bülent Ecevit University.

Informed Consent: Informed consent was obtained from the family or legal representatives of the patients included in the study.

Peer-review: Externally peer-reviewed.

Author Contributions: Concept - H.Y.; Design - H.Y., F.C.O.; Supervision H.Y., F.C.O.; Materials - H.Y, F.C.O; Data Collection and/or Processing - H.Y., F.C.O.; Analysis and/or Interpretation - H.Y, F.C.O.; Literature Search - H.Y, F.C.O., E.I.K.; Writing Manuscript - H.Y., F.C.O., E.I.K., C.K.; Critical Review H.Y., F.C.O., E.I.K., C.K.

Conflict of Interest: The authors have no conflict of interest to declare.

Financial Disclosure: The authors declared that this study has received no financial support.

\section{REFERENCES}

1. Proffit WR AJ. Orthodontics diagnosis: the devolopment of a problem list. Contemporary Orthodontics. 3rd ed: Mosby; 2000. p. 165-70.

2. Joffe L. Current products and practices OrthoCAD ${ }^{\mathrm{TM}}$ : digital models for a digital era. J Orthod 2004; 31: 344-7. [CrossRef]

3. Keating AP, Knox J, Bibb R, Zhurov Al. A comparison of plaster, digital and reconstructed study model accuracy. J Orthod 2008; 35: 191-201. [CrossRef]

4. Abizadeh N, Moles DR, O'Neill J, Noar JH. Digital versus plaster study models: how accurate and reproducible are they? J Orthod 2012; 39: 151-9. [CrossRef]

5. Han UK, Vig KW, Weintraub JA, Vig PS, Kowalski CJ. Consistency of orthodontic treatment decisions relative to diagnostic records. Am J Orthod Dentofacial Orthop 1991; 100: 212-9. [CrossRef]

6. Naidu D, Freer TJ. Validity, reliability, and reproducibility of the iOC intraoral scanner: a comparison of tooth widths and Bolton ratios. Am J Orthod Dentofacial Orthop 2013; 144: 304-10. [CrossRef]

7. Martin CB, Chalmers EV, McIntyre GT, Cochrane H, Mossey PA. Orthodontic scanners: what's available? J Orthod 2015; 42: 136-43. [CrossRef]

8. Kravitz ND, Groth C, Jones PE, Graham JW, Redmond WR. Intraoral digital scanners. J Clin Orthod 2014; 48: 337-47.

9. Goracci C, Franchi L, Vichi A, Ferrari M. Accuracy, reliability, and efficiency of intraoral scanners for full-arch impressions: a systematic review of the clinical evidence. Eur J Orthod 2016; 38: 422-8. [CrossRef]

10. Saleh WK, Ariffin E, Sherriff M, Bister D. Accuracy and reproducibility of linear measurements of resin, plaster, digital and printed study-models. J Orthod 2015; 42: 301-6. [CrossRef]

11. Salzmann JA WF. Interceptive preventive orthodontics. Orthodontics In Daily Practice. 5th ed: Philadelphia: Lippincott; 1974. p. 211-4.

12. Bolton WA. Disharmony in tooth size and its relation to the analysis and treatment of malocclusion. Angle Orthod 1958; 28: 113-30.

13. Bolton WA. The clinical application of a tooth-size analysis. Am J Orthod 1962; 48: 504-29. [CrossRef]

14. Rossini G, Parrini S, Castroflorio T, Deregibus A, Debernardi CL. Diagnostic accuracy and measurement sensitivity of digital models for orthodontic purposes: A systematic review. Am J Orthod Dentofacial Orthop 2016; 149: 161-70. [CrossRef]

15. Fleming $P$, Marinho V, Johal A. Orthodontic measurements on digital study models compared with plaster models: a systematic review. Orthod Craniofac Res 2011; 14: 1-16. [CrossRef]

16. Müller P, Ender A, Joda T, Katsoulis J. Impact of digital intraoral scan strategies on the impression accuracy using the TRIOS Pod scanner. Quintessence Int 2016; 47: 343-9.

17. Renne W, Ludlow M, Fryml J, Schurch Z, Mennito A, Kessler R, et al. Evaluation of the accuracy of 7 digital scanners: An in vitro analysis based on 3-dimensional comparisons. J Prosthet Dent 2017;118: 36-42. [CrossRef]

18. Santoro M, Galkin S, Teredesai M, Nicolay OF, Cangialosi TJ. Comparison of measurements made on digital and plaster models. Am J Orthod Dentofacial Orthop 2003; 124: 101-5. [CrossRef]

19. Grunheid T, McCarthy SD, Larson BE. Clinical use of a direct chairside oral scanner: an assessment of accuracy, time, and patient acceptance. Am J Orthod Dentofacial Orthop 2014; 146: 673-82. [CrossRef]

20. Tomassetti JJ, Taloumis LJ, Denny JM, Fischer Jr JR. A comparison of 3 computerized Bolton tooth-size analyses with a commonly used method. Angle Orthod 2001; 71: 351-7.

21. Stevens DR, Flores-Mir C, Nebbe B, Raboud DW, Heo G, Major PW. Validity, reliability, and reproducibility of plaster vs digital study models: comparison of peer assessment rating and Bolton analysis and their constituent measurements. Am J Orthod Dentofacial Orthop 2006; 129: 794-803. [CrossRef]

22. Leifert MF, Leifert MM, Efstratiadis SS, Cangialosi TJ. Comparison of space analysis evaluations with digital models and plaster dental casts. Am J Orthod Dentofacial Orthop 2009; 136: 16. e1-4. [CrossRef]

23. Wiranto MG, Engelbrecht WP, Nolthenius HET, van der Meer WJ, Ren Y. Validity, reliability, and reproducibility of linear measurements on digital models obtained from intraoral and cone-beam computed tomography scans of alginate impressions. Am J Orthod Dentofacial Orthop 2013; 143:140-7. [CrossRef]

24. Czarnota J, Hey J, Fuhrmann R. Measurements using orthodontic analysis software on digital models obtained by 3D scans of plaster casts: Intrarater reliability and validity. J Orofac Orthop 2016; 77: 22-30. [CrossRef]

25. Reuschl RP, Heuer W, Stiesch M, Wenzel D, Dittmer MP. Reliability and validity of measurements on digital study models and plaster models. Eur J Orthod 2015; 38: 22-6. [CrossRef]

26. Zhang F, Suh K-J, Lee K-M. Validity of intraoral scans compared with plaster models: an in-vivo comparison of dental measurements and 3d surface analysis. PloS One 2016; 11: doi: 10.1371/journal. pone.0157713. eCollection 2016. [CrossRef]

27. Flügge TV, Schlager S, Nelson K, Nahles S, Metzger MC. Precision of intraoral digital dental impressions with iTero and extraoral digitization with the iTero and a model scanner. Am J Orthod Dentofacial Orthop 2013; 144: 471-8. [CrossRef]

28. Alcan T, Ceylanoğlu C, Baysal B. The relationship between digital model accuracy and time-dependent deformation of alginate impressions. Angle Orthod 2009; 79: 30-6. [CrossRef]

29. Dalstra $M$, Melsen B. From alginate impressions to digital virtual models: accuracy and reproducibility. J Orthod 2009; 36: 36-41. [CrossRef]

30. Mullen SR, Martin CA, Ngan P, Gladwin M. Accuracy of space analysis with emodels and plaster models. Am J Orthod Dentofacial Orthop 2007; 132: 346-52. [CrossRef] 